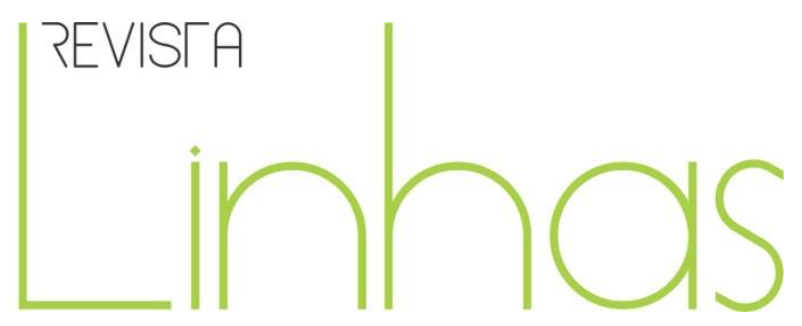

\title{
Fotografía, cultura física y deporte en la prensa de guerra republicana (1936-1939)
}

\begin{abstract}
Resumen
Durante la guerra civil española algunos grupos milicianos primero, y tras la desaparición de estos, el Comisariado General de Guerra editaron casi 500 publicaciones periódicas, con distinto formato, dentro de las unidades militares para su consumo exclusivo dentro del ejército. La tipología de artículos que contienen es variada, pero en general se usaron para trasladar a la tropa las consignas del gobierno republicano. Una de las principales preocupaciones de este fue la formación y educación de un ejército compuesto en un gran porcentaje por obreros y campesinos iletrados. Tras una revisión exhaustiva de la mayoría de los ejemplares que se conservan, hemos podido constatar que casi la mitad de estas publicaciones son ilustradas y contienen tanto fotografías como dibujos. Dentro de las temáticas educativas que desarrollan encontramos: alfabetización, cultura general, higiene, capacitación militar, cultura política y cultura física. Tomando estas publicaciones ilustradas como muestra, nuestra intención aquí es presentar una primera aproximación sobre cómo se usa la fotografía, en este tipo de prensa de guerra, para construir discursos sobre cultura física y el deporte.
\end{abstract}

Palabras clave: Guerra Civil Española. Cultura física. Prensa ilustrada. Fotografía.

\author{
Avelina Miquel Lara \\ Universitat de les Illes Balears - \\ España \\ avelina.miquel@uib.eu \\ Francisca Comas Rubí \\ Universitat de les Illes Balears - \\ España \\ xisca.comas@uib.es
}

\begin{abstract}
Para citar este artigo:
MIQUEL LARA, Avelina; COMAS RUBÍ, Francisca. Fotografía, cultura física y deporte en la prensa de guerra republicana (1936-1939). Revista Linhas. Florianópolis, v. 20, n. 44, p. 42-52, set./dez. 2019.
\end{abstract}

DOI: $10.5965 / 1984723820442019042$

http://dx.doi.org/10.5965/1984723820442019042

\footnotetext{
${ }^{1}$ Cultura y prácticas escolares en el siglo XX. EDU2017-82485-P. financiado por el Ministerio de Ciencia, Innovación y Universidades (MCIU), la Agencia Estatal de Investigación (AEI) y el Fondo Europeo de Desarrollo Regional (FEDER, UE). Este trabajo fue originariamente presentado como comunicación en las VIII Jornadas científicas de la SEPHE - I Congresso Nazionale della SIPSE celebrado en el mes de noviembre de 2018 en Palma de Mallorca y publicado en sus actas.
} 


\section{Photography, physical culture and sport in the republican war press (1936-1939)}

\begin{abstract}
During the Spanish Civil War some militia groups first, and after their disappearance, the General War Commissariat published almost 500 periodicals, with different formats, within the military units for their exclusive consumption within the army. The type of articles they contain is varied, but in general, they were used to transfer to the troop the slogans of the Republican government. One of the main concerns was the formation and education of an army made up of a large percentage of illiterate workers and peasants. After an exhaustive review of the majority of the copies that are preserved, we have been able to verify that almost half of these publications are illustrated and contain both photographs and drawings. Within the educational themes they develop we find: literacy, general culture, hygiene, military training, political culture, and physical culture. Taking these illustrated publications as a sample, our intention here is to present a first approximation of how photography is used, in this type of war press, to construct discourses on physical culture and sport.
\end{abstract}

Keywords: Spanish Civil War. Physical culture. Illustrated press. Photography.

\section{Fotografia, cultura física e esporte na imprensa de guerra republicana (1936-1939)}

\section{Resumo}

Durante a guerra civil espanhola, alguns grupos milicianos em primeiro lugar e, depois do desaparecimento destes, o Comissariado Geral de Guerra editaram quase 500 publicações periódicas, com formatos diferentes, nas unidades militares para $O$ seu consumo exclusivo dentro do exército. A tipologia de artigos que contêm é variada, mas em geral foram usados para transmitir às tropas as instruções do governo republicano. Uma das principais preocupações deste foi a formação e a educação de um exército composto em grande porcentagem de operários e camponeses iletrados. Após uma revisão exaustiva da maioria dos exemplares que se conservam, pudemos constatar que quase a metade dessas publicações são ilustradas e contêm tanto fotografias quanto desenhos. Dentro das temáticas educativas que desenvolvem, encontramos: alfabetização, cultura geral, higiene, capacitação militar, cultura política e cultura física. Tomando essas publicações ilustradas como amostra, nossa intenção aqui é apresentar uma primeira aproximação sobre como se usa a fotografia, neste tipo de imprensa de guerra, para construir discursos sobre a cultura física e o esporte.

Palavras-chave: Guerra Civil Espanhola. Cultura física. Imprensa ilustrada. Fotografia. 


\section{Introducción}

Tras el alzamiento militar del 18 de julio de 1936, que supuso el inicio de la Guerra Civil española, surgieron grupos milicianos dispuestos a defender la legalidad y la República. Algunos de ellos estaban vinculados a partidos, asociaciones y sindicatos de izquierda que empezaron a editar publicaciones periódicas orientadas a los milicianos. Tras la creación del Comisariado General de Guerra por decreto del 15 de octubre de 1936, este centralizó todas estas publicaciones bajo su control y promocionó la creación de nuevas revistas y periódicos en todas las unidades militares (Nuñez, 1992). Son las que conforman la llamada prensa de guerra republicana, publicadas por y para los combatientes. A través de ellas se hacía llegar a las tropas las consignas del Gobierno y del Comisariado y se daba cabida a las preocupaciones de los soldados.

La tipología y periodicidad de estas publicaciones fue heterogénea. Encontramos publicaciones diarias, semanales, decenales, quincenales, mensuales, etc. y en formato de boletín, diario, periódico o revista. En total se han catalogado unas 500 publicaciones (Soria, 1978). Como parte de un proyecto de investigación más amplio que estamos desarrollando, y que trasciende el ámbito de este artículo, hemos seleccionado y analizado las que son ilustradas. Hemos considerado como tales las que contienen tanto fotografía como dibujo en un porcentaje igual o superior al $15 \%$, desestimando aquellas con un porcentaje menor por entender que en ellas la imagen no desempeña un papel principal en la transmisión de ideas o mensajes. Del medio millar de publicaciones mencionadas, se han seleccionado 228 , que son las que cumplen con los porcentajes mínimos de ilustración, y cuyos títulos se pueden consultar en Miquel y Comas (2018).

Además de la transmisión de mensajes y consignas útiles para la guerra estas revistas tenían un claro componente educativo. La creación de una ciudadanía consciente y libre siempre fue uno de los objetivos de la República mientras gobernó la izquierda, que desarrolló una política educativa de influencia institucionista. La guerra supuso una oportunidad para retomar las antiguas ambiciones formativas que habían quedado aplazadas durante el bienio negro, aunque cabe decir que en cierta forma también supuso una pérdida de la neutralidad que debiera acompañar la enseñanza. Las 
circunstancias bélicas impusieron una educación revolucionaria en las escuelas (Fernández, 1984), y cómo no, en el ejército. La educación de las tropas atendía un doble objetivo. Por una parte, preparaba una ciudadanía libre para la vida después de la guerra. Por la otra, urgía formar los soldados ya que era casi imposible ganar la guerra con un ejército con un alto porcentaje de analfabetos. Se convirtió en absolutamente necesario que los soldados supieran entender un plano, leer instrucciones, calcular una trayectoria balística y otras cuestiones relacionadas con los avances tecnológicos bélicos o los preceptos de la guerra moderna.

A pesar de esto último, los artículos educativos no sólo estaban orientados hacia la técnica militar. Se aspiraba también a una formación integral, por ello encontramos numerosos artículos dedicados a la promoción de la alfabetización, la lectura, la adquisición de cultura política, el desarrollo moral, el fomento de la higiene y la cultura física.

Se consideraba que un ejército que practicase gimnasia y deporte tendría una mejor disposición al triunfo, y en gran medida esta idea formaba parte del discurso de los artículos relacionados con la cultura física. Aun así, otras facetas educativas del deporte, como el desarrollo integral que incluye el binomio cuerpo y mente, aparecen también de forma reiterada en la prensa de guerra analizada.

\section{La Cultura Física y el deporte en la prensa de guerra republicana}

Existe un paralelismo ente el deporte y la guerra ya que aquel representa a pequeña escala, y dentro de unas normas de juego, la reproducción de batallas. Además, supone un medio de entrenamiento ameno y apetecible al tiempo que fomenta el espíritu de equipo, el compañerismo, el respeto a las reglas, la disciplina y “promueve un modelo muy concreto de masculinidad" (Torrebadella-Flix, 2016a, p. 173), características que cualquier ejército desearía para sus tropas. En este sentido no es de extrañar que desde el Comisariado General de Guerra se diseñase una campaña de fomento de la gimnasia y el deporte entre los soldados republicanos. Esta campaña para su funcionamiento se valió de estructuras como la participación de la preexistente Federación Cultural Deportiva y 
Obrera, F.C.D.O., la creación en las divisiones de Inspecciones de Cultura Física o la dotación de monitores de Cultura Física para las unidades militares y contó con la prensa de guerra como altavoz.

Durante la I Guerra Mundial en la prensa de masas, que justo en esos años estaba desarrollándose en Europa (Álvarez et al., 1989), se produjo una imbricación del lenguaje bélico y deportivo (Torrebadella-Flix, 2016b). Las gestas deportivas se narraban como eventos bélicos y viceversa. Además, la prensa especializada ya estaba consolidada con publicaciones como Stadium (1911-1930), Madrid-Sport (1916-1925), Heraldo Deportivo (1915-1935) o El Mundo Deportivo (1906-1938), por citar algunos (Simón, 2014). El Comisariado General de Guerra, al usar sus publicaciones para promocionar el deporte, contaba pues con una tradición editorial heredada y una audiencia acostumbrada a la lectura de temas deportivos.

Entre las motivaciones de este organismo para publicitar el deporte encontramos su capacidad para "impulsar movimientos moralizadores y nacionalizadores" (Torrebadella-Flix, 2016a, p. 173). Por tanto, es comprensible que, en una guerra ideológica como la Guerra Civil, el ejercicio físico fuese utilizado como un elemento cohesivo de las tropas y de difusión del modelo republicano de estado. Por otro lado, la cultura física y el deporte formaban parte del ideal institucionista relativo a la educación integral que tanta influencia tuvo en las políticas educativas republicanas, aspecto que también fue objeto de debate en la prensa de guerra editada por el Comisariado. Queda claro que el interés por el deporte respondía a una doble finalidad, la estrictamente bélica y la educativa.

La extensión de este artículo no nos permite ser exhaustivos en el análisis de los artículos que contienen referencias y fotografías deportivas ni de los discursos visuales que estas proporcionan, pero sí realizar una primera aproximación a estas cuestiones. 


\section{Cultura física y deporte en la prensa de guerra republicana: una primera aproximación iconográfica}

Son muchas las implicaciones educativas, morales, ideológicas y médico-higiénicas de la cultura física y el deporte que son tratadas en diferentes artículos e ilustradas con fotografías a lo largo de los 3 años de guerra en estas publicaciones. En futuras investigaciones tenemos la intención de ahondar en estas cuestiones, pero dadas las limitaciones de espacio en esta ocasión nos limitamos a señalar algunos de los elementos iconográficos empleados para promocionar el deporte entre los soldados y valorar otros mensajes visuales implícitos que puedan contener como parte de un currículum oculto de la educación física. Cabe destacar que en muchos de los artículos publicados se reconoce que una parte de los soldados no entendían la necesidad de participar en las clases de gimnasia y deporte y que por ello fue necesario estimular su práctica a través de una campaña.

En nuestra investigación sobre la educación física y el deporte en el ejército republicano durante la Guerra Civil en total hemos encontrado 302 artículos referentes a esta temática en la prensa de guerra. De ellos 171 contienen al menos una fotografía y 131 no incluyen ninguna, aunque en ocasiones van ilustrados con algún dibujo. Después de analizar tanto el texto como las fotografías de estos reportajes referidos a la cultura física y el deporte, podemos avanzar que se identifican tres discursos construidos con ayuda de la imagen: la idea del héroe solitario, la de pertenencia al grupo y la de la aplicación militar de la cultura física y el deporte. 

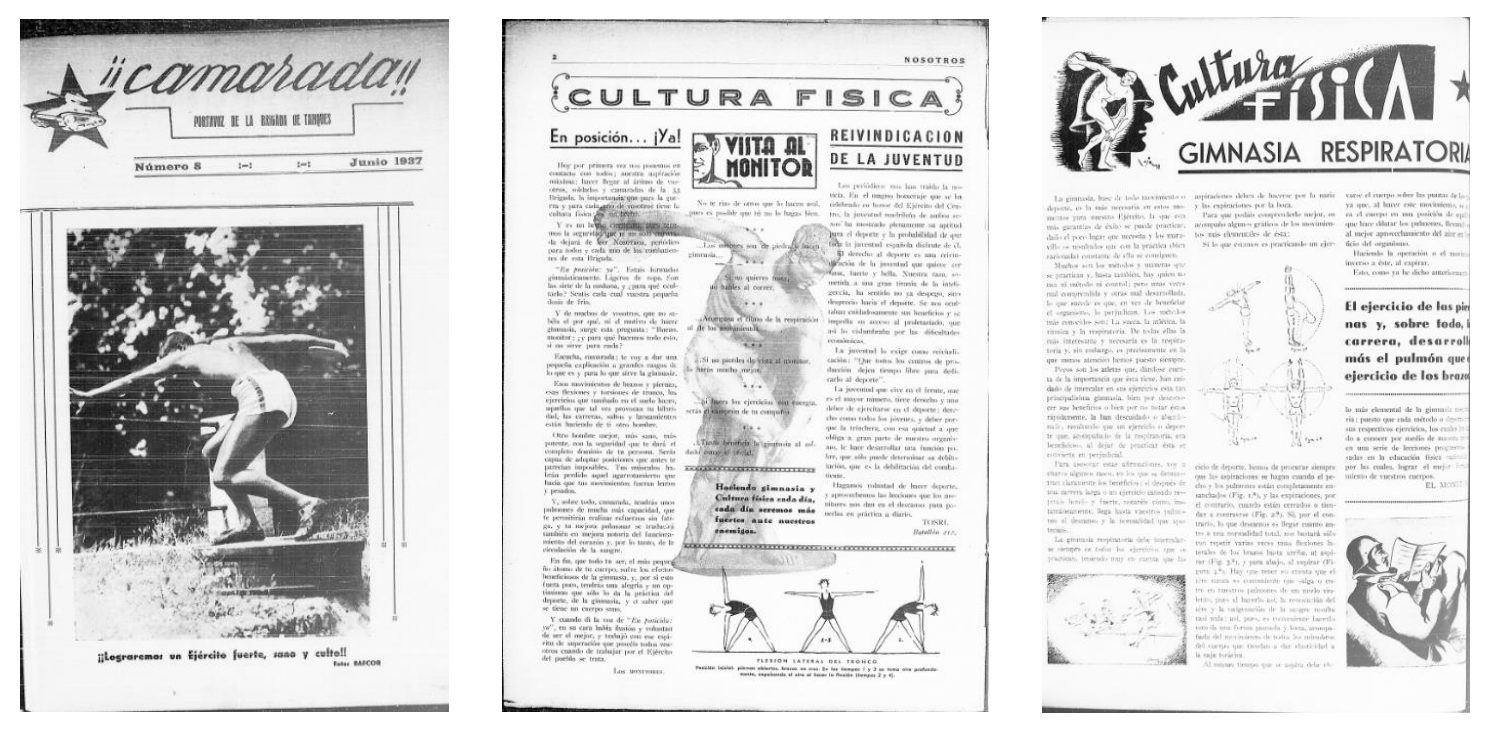

Foto 1 iiCamarada!! Portavoz de la Brigada Tanques $\mathrm{n}^{\circ} 8$.

Foto 2: Nosotros. Órgano de la 53 Brigada Mixta $n^{\circ} 1$.

Foto 3: Ruta $n^{\circ}$ 4. Fuente: Hemeroteca Municipal de Madrid.

Las fotografías y grafismos que recuerdan al atleta clásico son frecuentes en estas publicaciones, hasta el punto de que en ocasiones llegan a ocupar la portada de la revista (foto 1) o formar parte de la cabecera de la sección dedicada al deporte (foto 3). Además, hemos encontrado algunos artículos donde se realiza un breve recorrido por la historia del deporte en los que se destaca el valor que se le daba tanto en Esparta como en la antigua Grecia al deporte. Por poner un ejemplo, el aparecido en el $n^{\circ} 28$ de Transporte en Guerra. Las referencias a los atletas de la antigüedad aparecen también en otros artículos. El mensaje iconográfico del atleta como reflejo del héroe solitario está implícito. El reconocimiento público, la fotografía singularizada, la difusión del nombre, y los logros alcanzados, el lugar preeminente en las publicaciones son elementos con los que se pretende apelar a la necesidad de reconocimiento y pervivencia que todos poseemos. La autoimagen queda así interpelada por un modelo a imitar. Un atleta/héroe que destaca sobre sus compañeros y que merece los honores y el aplauso de los demás sin duda es un reclamo publicitario para promocionar el deporte en el ejército.

En lo pedagógico-deportivo estas imágenes también transmiten un mensaje respecto al tipo de cultura física que se desea difundir. Sobre todo, se promocionaron los ejercicios orientados a procurar un desarrollo armónico del cuerpo con connotaciones 
médico-higiénicas. El objetivo era conseguir un cuerpo flexible, hábil y resistente al esfuerzo físico, por encima del híper-desarrollo de determinados grupos musculares, como reflejo de un estado de salud óptimo y la adaptación a las diferentes necesidades de la guerra. Este concepto de desarrollo armónico no solo corresponde a principios higiénicos o de aplicación militar, se encuadra también dentro de la lógica de la formación integral institucionista que se promovía desde el gobierno de la República como reflejo del equilibrio necesario entre la formación intelectual y la física.
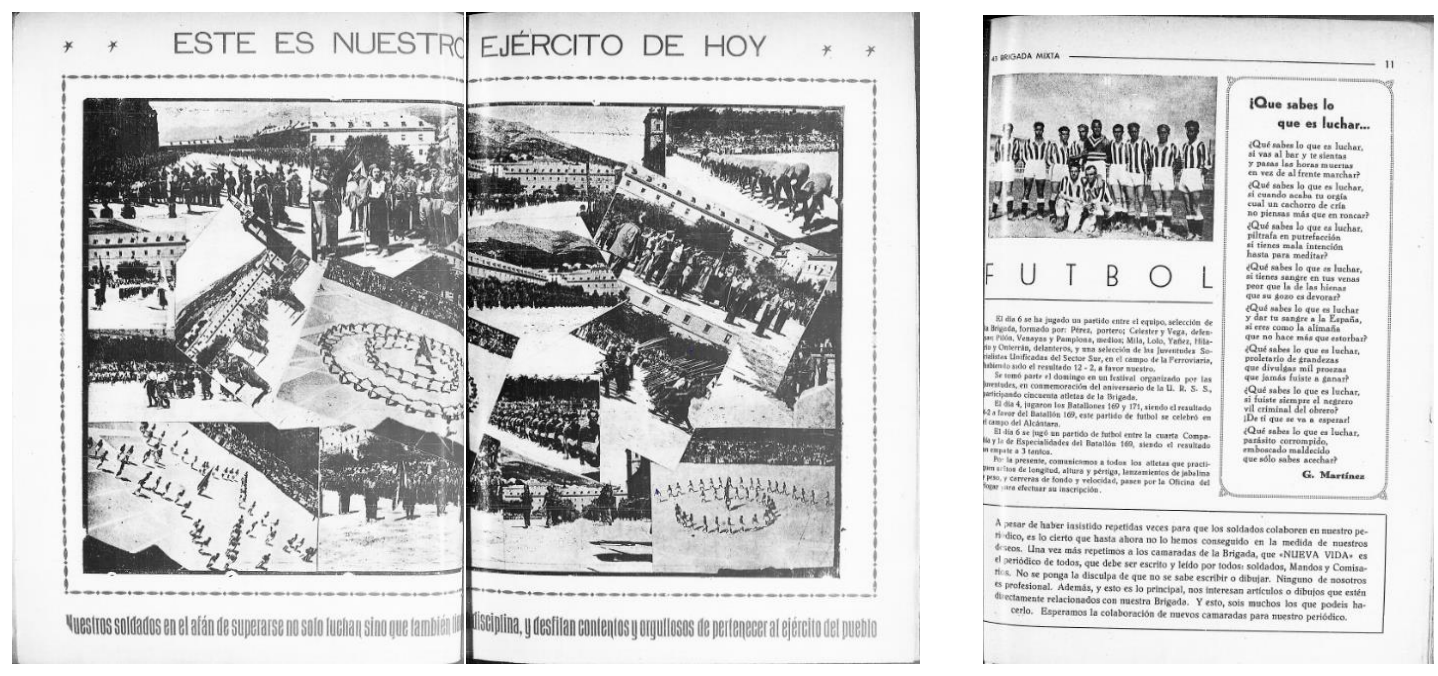

Fotos 4 y 5 Nuestro Ejército. Órgano de la Tercera División $n^{\circ} 9$.

Foto 6: Nueva Vida. Órgano Oficial de la 43 Brigada Mixta $n^{\circ}$ 2. Fuente: Hemeroteca Municipal de Madrid.

A pesar de las invocaciones al héroe clásico por las imágenes singularizadas lo cierto es que las guerras en ese momento precisaban del trabajo conjunto y orgánico de las tropas. Por ello las fotografías de conjunto donde un grupo numeroso de soldados ejecutan ejercicios físicos o practican deporte en equipo responden a un doble discurso. Por una parte, le dicen al soldado que no está solo, que a pesar de que la guerra supone un gran cataclismo emocional y físico puede contar con el grupo, que forman parte de algo mayor, de una comunidad. Esta idea viene corroborada por la leyenda superior del artículo de las fotografías 4 y 5 "Este es nuestro ejército de hoy" (Nuestro Ejército, 9). Con ello se le señala al soldado de qué comunidad forma parte, el ejército, al tiempo que se reafirma la pertenencia con el posesivo nuestro. 
Por otra parte, las imágenes de grupos ejercitándose conjuntamente o formando equipos deportivos refuerza la idea de disciplina. El ejército republicano estaba formado en gran parte por obreros y campesinos que en primera instancia formaron parte de un ejército miliciano y que luego se integraron en el ejército regular. Esta integración fue especialmente costosa para los anarquistas que se mostraron reticentes a aceptar la disciplina o el saludo militar. En ese momento ya era bien conocida la capacidad moralizante y educativa de los deportes de equipo que acostumbran a obedecer a un líder o capitán, a sujetarse a unas normas, a adquirir una mayor resistencia a la frustración, a evaluar con rapidez las situaciones y tomar decisiones (Torrebadella-Flix, 2016b). Por ello el Comisariado general de Guerra no dudó en hacer pedagogía de estos conceptos a través de los deportes y las actividades gimnásticas grupales.
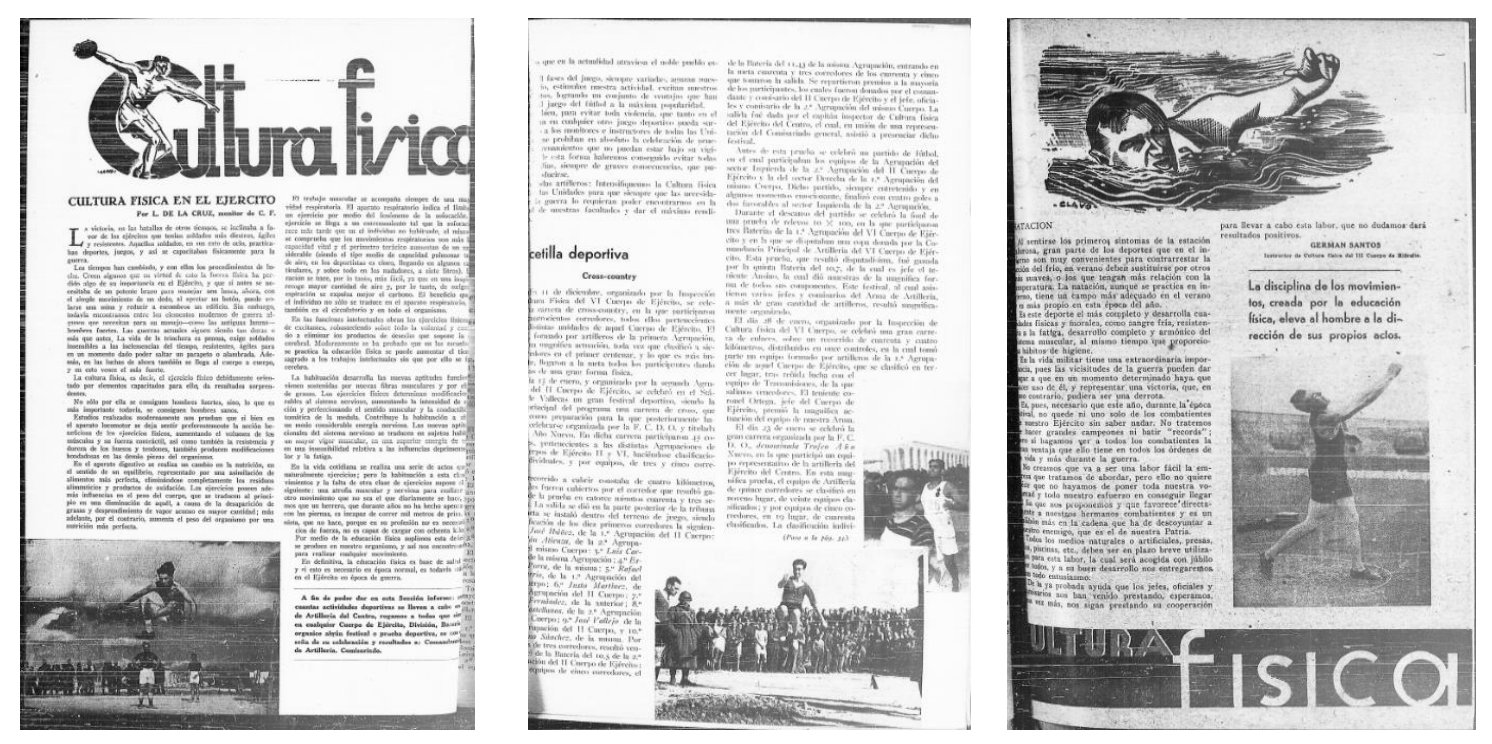

Foto 7: ¡A sus puestos! Revista político-militar $n^{\circ} 1$.

Foto 8: $¡$ A sus puestos! Revista política-militar $n^{\circ} 2$.

Foto 9: ¡A sus puestos! Revista político-militar $n^{\circ}$ 5. Fuente: Hemeroteca Municipal de Madrid.

Otra faceta deportiva que se publicitó fue su aplicación militar. Algunos deportes como el salto de altura y longitud, las carreras, el lanzamiento de disco, jabalina, peso, bomba o barra castellana, entre otros, se consideraban especialmente útiles para la guerra. A la hora de asaltar una posición el poder moverse con rapidez y sin cansarse a 
medio camino, ser capaces de saltar parapetos y otros obstáculos, así como lanzar con precisión y fuerza bombas de mano se consideraba especialmente útil. Por ello este tipo de deportes se incluyó en la mayoría de festivales deportivos celebrados. El deporte en este sentido se convirtió en un arma antifascista más. Un elemento útil para ganar la guerra y derrotar a los fascistas según el lenguaje empleado en estas publicaciones. Por otra parte, ganar la guerra suponía el paso previo para poder establecer una sociedad donde el deporte fuese un derecho para todos los ciudadanos como parte de su formación integral.

\section{Conclusiones}

Durante la Guerra Civil española el gobierno republicano a través del Comisariado General de Guerra organizó una campaña de difusión del deporte y la cultura física entre los soldados. Esta campaña respondía tanto a aspectos educativos como bélicos.

Siguiendo los preceptos de formación integral se dispuso la alfabetización del mayor número de soldados posible junto a una formación física de carácter higiénicopedagógica, además de con aplicación militar.

De forma sucinta hemos querido aproximarnos a las motivaciones que llevaron a esta campaña de difusión del deporte, a los mensajes utilizados y a los elementos visuales que reforzaron estos mensajes.

Iconográficamente hemos destacado tres ideas. La primera hace referencia al valor y al reconocimiento del soldado a través de la imagen del atleta clásico. La segunda a la importancia del deporte de grupo como arma pedagógico-disciplinaria y elemento cohesionador. La última al concepto de deporte como arma antifascista por su aplicación militar. Aunque esta última idea subyace en los otros discursos, es en el deporte de aplicación donde se desarrolla de manera manifiesta.

Para finalizar nos gustaría insistir en el carácter iniciático de esta comunicación a un tema que continuamos investigando y que puede aproximarnos a un mejor conocimiento de la educación deportiva durante la Guerra Civil. 


\section{Referencias}

ÁLVAREZ, Jesús; et al. Historia de los medios de comunicación en España. Periodismo, imagen y publicidad (1900-1990). Barcelona: Ariel, 1989.

FERNÁNDEZ, Juan Manuel. La educación en la España Republicana durante la guerra civil (1936-1939). Bordón. Revista de pedagogía, n. 252, p. 24-270, 1984.

MIQUEL, Avelina y COMAS, Francisca. The War Child. Childhood photographed in the Republican military press during the Spanish Civil War (1936-39). History of Education and Children's Literature, Special Issue about "Images of the European Child”, v. 13, n. 1, p. 410-432, 2018.

Nuestro Ejército. Órgano de la Tercera División. N. 9, s.p., 1937.

NÚÑEZ DÍAZ-BALART, Mirta. La prensa de guerra en la zona republicana durante la guerra civil española (1936-1939). Madrid: Ediciones de la Torre, 1992.

RIAZA, David. Transporte en Guerra. Órgano del servicio de Tren del Ejército. n. 28, s.p., 1938.

SIMÓN, Juan Antonio. Deportistas en las trincheras de Europa: La Primera Guerra Mundial y su impacto en la prensa deportiva española. Podium Sport, Leisure and Tourism

Review, v. 3, n. 2, p. 97-111, 2014.

SORIA, Georges. Guerra y Revolución en España (1936-1939). Barcelona: Ediciones Grijalbo, 1978.

TORREBADELLA-FLIX, Xavier. La bibliografía gimnástica y deportiva de la educación física en el ejército español (1808-1919): textos en contexto social. Revista Universitaria de Historia Militar, v. 5, n. 9, p. 173-192, 2016a.

TORREBADELLA-FLIX, Xavier. Institucionalización del fútbol en el ejército español (19191920). Orígenes del patrioterismo futbolístico nacional. El futuro del pasado, n. 7, p. 497$532,2016 b$. 